ISSN 0103-7013

Psicol. Argum., Curitiba, v. 28, n. 63, p. 351-357 out./dez. 2010

Licenciado sob uma Licença Creative Commons

\title{
Práticas cotidianas de proteção à infância: Movimentos de (pre)ocupação com quem?
}

\author{
Daily practices of protection to the infancy: \\ Movements of (pre)occupation with whom?
}

\author{
Luciana Rodrigues $^{[\mathrm{a}]}$, Lílian Rodrigues da Cruz ${ }^{[\mathrm{b}]}$
}

[a] Psicóloga, Graduada pela Universidade de Santa Cruz do Sul (UNISC), Mestranda em Psicologia Social e Institucional da Universidade Federal do Rio Grande do Sul (UFRGS), Porto Alegre, RS - Brasil, e-mail: luciana_rodrig@yahoo.com.br

[b] Doutora em Psicologia pela Pontifícia Universidade Católica de São Paulo (PUC-SP), docente e pesquisadora do Departamento de Psicologia e do Mestrado em Letras na Universidade de Santa Cruz do Sul (UNISC), Santa Cruz do Sul, RS - Brasil, e-mail: liliancruz2@terra.com.br

\section{Resumo}

Este artigo é fruto das inquietações de uma prática acadêmica no Conselho Tutelar em um município de médio porte do Estado do Rio Grande do Sul. A escritura se compõe de recortes do cotidiano, em que o fazer/pensar coletivo interroga o lugar da psicologia e sua indissociabilidade com a política. A partir de um olhar cartográfico, objetiva-se colocar em análise determinadas práticas dirigidas à infância, problematizando a naturalização das ações, como a incomunicabilidade entre os operadores de direitos que compõem a rede de atendimento à infância. Além de interrogar o lugar que a psicologia tem ocupado nestes espaços, pretende-se discutir possíveis brechas nos instituídos, propondo ações para potencializar os sujeitos inseridos nos variados programas de atendimento à infância.

Palavras-chave: Infância. Políticas públicas. Conselho tutelar.

\begin{abstract}
This article is derived from the anxieties of an academic practice in Tutelary Council in a town of average load in Rio Grande do Sul State. The writing is composed by cuttings of the daily, where the collective doing/thinking interrogates the psychology place and its non-dissociation with the politics. Starting from a cartographic glance, we have aimed to put in analysis certain practices adressed to the infancy, problematizing the actions' naturalization, as the incommunicativeness among the operators of rights who compose the service net to the infancy. Besides inter-
\end{abstract}


rogating the place that the psychology has been occupying in these spaces, we intended to discuss possible breaches in the instituted, proposing actions to potentiate the subjects inserted in the varied service programs to the infancy.

Keywords: Infancy. Public policies. Tutelary council.

\section{Contextualizando a proposta}

Este artigo é fruto das inquietações de uma prática acadêmica na rede de atendimento à infância de município de médio porte do Estado do Rio Grande do Sul. Entende-se por práxis acadêmica o conjunto de ações/reflexões realizadas, seja no papel de estudante de Psicologia, supervisora, estagiária, docente e/ou pesquisadora. A partir de recortes do cotidiano do Estágio Integrado em Psicologia da primeira autora no Conselho Tutelar do município, sob supervisão da segunda autora, objetivou-se colocar em análise determinadas práticas dirigidas à infância, problematizando a naturalização de algumas ações. Além de interrogar o lugar que a psicologia tem ocupado nesses espaços, este trabalho aponta possíveis brechas nos instituídos. Como ferramenta metodológica, utilizou-se o olhar cartográfico, conforme proposto por Deleuze e Guattari, à medida que possibilita acompanhar e investigar os processos de produção, em vez de representar um objeto. Nesse caminho não há uma coleta de dados, mas uma produção dos dados da pesquisa que convoca a assumir a atenção, não como seleção de informações, mas como "detecção de signos e forças circulantes, ou seja, de pontas em processo em curso" (Kastrup, 2007, p. 15).

\section{Discursos cotidianos no cenário da infância}

O Estatuto da Criança e Adolescente (BRASIL, 1990) dispõe sobre a composição dos Conselhos Tutelares com base no princípio de zelar pelo cumprimento dos direitos das crianças e adolescentes, o que faz mediante as atribuições postuladas nele. Ao acompanhar os movimentos cotidianos de um Conselho Tutelar (CT), é possível observar que muitas das ações, que deveriam zelar pela proteção e por um cuidado a crianças e adolescentes, assumem um automatismo diante da produção das urgências e do elevado número de demandas (denúncias, encaminhamentos, etc.) que "precisam ser atendidas".
Esse automatismo, que conduz a práticas instituídas e naturalizadas, é acompanhado de discursos que (re) afirmam a culpabilização da família - 'desestruturada', 'negligente', 'sem condições de criar os filhos', etc., produzindo uma individualização e responsabilização da pobreza, ou seja, a família é responsável por sua condição. Isso pode ser constatado, por exemplo, em muitos programas de atendimento à família que colocam como primeiro item a reversão da situação que originou o ingresso no programa, ou seja, a família precisa reverter seu estado de vulnerabilidade social.

$\mathrm{O}$ modo de enfrentamento à excessiva demanda que chega ao CT nos remete às práticas de sobreimplicação que trazem a crença no sobretrabalho e no ativismo das práticas. Isso acelera a necessidade de se obter soluções rápidas e competentes pelo acúmulo de tarefas e pela produção de urgência (Coimbra \& Nascimento, 2007), que, aliados ao contexto contemporâneo, em que o tempo parece reduzir-se, forjam as urgências e aceleram as soluções, mantendo o instituído à medida que sobra pouco espaço para a reflexão. Dessa forma, a ação dos operadores de direitos se torna também individualizada e dicotomizada, pois nem se articula com a rede de atendimento, nem fomenta a formação de coletivos.

Há um discurso que (re)produz um descrédito na resolutividade das ações e medidas protetivas, acarretando o esvaziamento de possibilidades, em que nada parece possível. Em um espaço atravessado pelo discurso de um "sistema falido" e "quebrado", um "estrangeiro" (como o estagiário de Psicologia) deve perceber que tudo o que "aprendeu é teoria, que na prática é diferente". Evidencia-se a desimplicação política dos sujeitos encarregados de fazer cumprir a lei e zelar pelos direitos das crianças e adolescentes na produção das relações de um "sistema" do qual falam, mas no qual não se incluem. Esse discurso que distancia teoria e prática compõe e forja a micropolítica das práticas cotidianas.

Como exemplo, trazemos fragmentos da história de Adriano $^{1}$ e sua família, visível pelo

1 Todos os nomes são fictícios. 
estigma da loucura e da pobreza. A visita à família de Adriano é realizada a partir da denúncia de que eles estariam "tomando banho pelados" (o que nos permite questionar tal demanda), ocorrida após a mudança de endereço da família, retirada de um lugar de visibilidade da cidade.

Ao chegar à "casa dos Adriano", o CT imediatamente passou a averiguar quais das sete crianças estavam em idade escolar, considerando a recente troca de endereço, apesar da notória descrença quanto às potencialidades delas, pois as meninas "não iriam ficar na escola mesmo". A escola, localizada perto da residência, foi visitada na mesma ocasião, a fim de efetivar a transferência das crianças. A instituição também não quis acolhê-las, já que as mesmas só iriam atrapalhar: "não tem mais de 27 lugares... não tem onde colocar as classes". Onde haveria lugar para as crianças?

\section{Do invisível ao excessivo}

No fluxo do tempo mais urgências surgem (daquilo que "salta" aos olhos), tornando exemplares as demandas escolares que se repetem. A escola sempre (a)parece com mais um encaminhamento, um aluno que incomoda, que não quer estudar, que briga, agride, demarcando o cotidiano com atuações de um dizer que chama, grita, apela o olhar. Diante de situações que desestabilizam a ordem do esperado, exige-se uma solução rápida, um novo encaminhamento que solicita ao CT orientação e solução para as crianças consideradas bagunceiras, prioritariamente que as conduzam aos serviços especializados. Assim, se Paulo não está querendo ir à escola, encaminhase a um serviço que ofereça psicoterapia, pois os conflitos (em sua maioria) são familiares e quem deve dar conta dessa questão é a psicologia, bem como os problemas que envolvem a aprendizagem e as relações conflituosas entre professor e aluno.

$\mathrm{Na}$ tentativa de problematizar os discursos fixos do fazer cotidiano, procurou-se "trazer à tona um olhar que, desnaturalizado, não está em busca de uma verdade que se ajuste às subjetividades dominantes, mas sim procura analisar os efeitos e as implicações das formas como vê, entende e age no mundo" (Matos \& Torralba, 2002, p. 77). Pouco espaço existe ao questionamento de práticas tão naturalizadas, o que institui a obrigatoriedade do atendimento de demandas produzidas pelos "pontos cegos" da sociedade e, principalmente, pela falta de políticas públicas que possam dar suporte às famílias.

Ainda em relação às escolas, um ponto parece intocado: a implicação dos processos de escolarização que atravessa os sujeitos na produção dos encaminhamentos. Questão que demanda à psicologia o "concerto" dos produtos de um processo da construção de uma realidade, como o fracasso escolar, quando o trabalho do psicólogo deveria, ao contrário, incidir sobre a própria construção dessa realidade (Heckert \& Barros, 2007). E tal reflexão não poderia ser transposta ao fazer conselheiro? No entanto, o encaminhamento parece consagrado na relação CT-escola: "não adianta vir a psicologia questionar demandas [...] se encaminham para cá, a gente atende $[. .$.$] se vem para cá é porque precisa”.$

Quantas situações permanecem na invisibilidade quando as ações não comportam medidas de proteção (previstas no ECA), ao contrário, contribuem para estigmatizar ainda mais as crianças (como na família de Adriano), diante das situações de violação de direitos? Causa estranhamento que denúncias anônimas sobre a exploração sexual infantil sejam discutidas em reunião coletiva para decidir se a situação será ou não registrada, ao passo que demandas comportamentais dos alunos são acolhidas sem qualquer questionamento.

O parâmetro para as urgências parece centrar-se naquilo que acumula, transborda. Ao mesmo tempo parece ser visível e enunciável apenas o que interessa... Mas a quem? Quais urgências que não falam de violação de direitos estarão se sobrepondo ao fazer conselheiro, que não possibilita brechas a uma reflexão acerca da sobreimplicação de suas práticas?

As práticas do CT também estão adquirindo um modelo jurisdicional. As decisões, de modo semelhante a um juiz, ficam a cargo do conselheiro, sem passar por discussões coletivas, constituindo mais um território de ação personalizada. Cada atendimento é uma sentença individual - prática não questionada e vista como mais adequada, encobrindo possíveis faltas e omissões das políticas públicas (Nascimento $\&$ Sheinvar, 2007). Seguindo as reflexões das autoras, no próprio CT se estabelecem estruturas hierárquicas e diferentes formas de atuação que contribuem para uma individualização das práticas, que, por sua vez, tem como efeito um processo de culpabilização quando há impossibilidade de atendimento, isso é visto pela família, sociedade e CT como falta de engajamento e/ou incapacidade pessoal, e raramente 
a ausência de políticas publicas é mencionada, pois "[...] quando não se tem como foco de ação a luta por políticas públicas, vão sendo fortalecidas subjetividades impotentes, faltosas e culpabilizadas, construídas por processos de individuação" (Nascimento \& Sheinvar, 2007, p. 158). Movimentos perceptíveis na relação do CT com escolas e famílias, na qual emerge o "aluno problema" (com seus conflitos), com famílias e mães "loucas".

A individualização como intervenção às problemáticas de produção social possibilita uma reflexão sobre as transformações que o contexto familiar vem sofrendo no contemporâneo. Se há tempos a família perpetuava laços comunitários, estabelecendo um convívio público que perpassava a educação e o cuidado dos sujeitos nela implicados, atualmente vem tornando-se um núcleo privado, responsabilizado pelas ações de seus membros. Scheinvar (2006, p. 50) demonstra que a família, no mundo moderno, tornouse um dispositivo de privatização do social, um espaço privado no qual a referência está no indivíduo. É na família que incide a responsabilidade pelos sujeitos, o que permite que sejam convocadas legalmente "para responder por qualquer movimento tido como fora dos padrões de normalidade instituídos". Nesse sentido, a família é convocada a explicar e responder pelas ações inadequadas de seus filhos, recaindo sobre ela a culpa do que não transcorre dentro do esperado. Famílias que, pela condição econômica e social, são, muitas vezes, atreladas ao discurso da negligência, da falta de cuidados e desinteresse pelos filhos. Sujeitos sem direito à escuta, mas com a obrigatoriedade da fala e o peso da culpa.

Para ilustrar, citamos uma visita domiciliar para advertência de evasão escolar, que teve como dispositivo de intervenção familiar o encaminhamento de uma Ficha de Comunicação ao Aluno Infreqüente (FICAI). Fomos recebidos pela mãe, que se queixava do filho revoltado que não queria mais ir à escola. Ela explicou que tinha outros filhos para cuidar e perguntou ao CT se não teria um lugar para interná-lo, do qual ele retornasse para visitar uma vez por mês. Uma primeira análise nos remeteria à negligência e/ou abandono da progenitora, no entanto, podemos pensar que a família está negligenciada pelas políticas. Como nos fala Scheinvar (2008, p. 179), as práticas dos CTs, no lugar de ressarcir os direitos, estariam contendo "alguns dos perversos efeitos da pobreza, da exploração, da disseminação da violência, do autoritarismo com que vem sendo gerido o Brasil”.

$\mathrm{Na}$ mesma situação, emerge um discurso individualista, condescendente com a lógica neoliberal, pois qual é a imposição que obriga crianças a voltarem à escola se não aquela que ameaça dizendo: "como você vai querer comprar o tênis que quer se não estudar? Como você será ser alguém na vida?" A culpa e ameaça marcam presença na advertência que convoca a mãe a ser chamada pela promotoria e ter que pagar uma multa com um dinheiro que não sabe de onde irá tirar, tudo por culpa de seu filho que não quer estudar. Scheinvar (2006) demonstra que os CTs, em uma sociedade de controle, excedem as concepções de cidadania, trilhando os caminhos de uma formação pedagógica, constituindo tanto um veículo de afirmação das relações autoritárias, quanto uma brecha aos processos de democratização. A família, ao ser alvo de cobrança do controle social, passa a ser um dispositivo de privatização do social que, "no entanto, não é produzida no sentido de analisar, debater, propor e intervir, enfim, nos processos em que se vê imersa" (Scheinvar, 2006, p. 55).

Intervenções que geram cobranças vazias, pois o que significa dizer a uma mãe que ela receberá uma multa quando é visível, por suas condições de vida, que não terá como pagá-la? Ou considerar o caso resolvido com o encaminhamento da criança a uma fila quase interminável de um serviço de saúde mental que não se sabe quando disponibilizará o atendimento? Há um esvaziamento das cobranças, um pacto do faz de conta entre o CT e as famílias, por meio do qual um finge que cobra e o outro finge que acredita (Kuhn, 2008).

Em meio às práticas e pactos que reatam o curso naturalizado da vida, crianças e adolescentes decidem por si, diante dos discursos familiares de impotência ("mas ele não quer ir à escola", "não sei o que fazer") o caminho a seguir. A família também solicita ao CT a imposição da autoridade. Segundo Kehl (2003), a dificuldade de impor limites aos filhos, quando o adulto não consegue bancar sua diferença diante deles, barra a transmissão de parâmetros éticos. Há, assim, um abandono moral que deixa a cargo das crianças a tomada de escolhas e decisões. Para a autora, possibilitar a transmissão de parâmetros éticos não depende apenas das famílias, mas da revalorização dos espaços públicos e da retomada das políticas públicas. 
As ações do CT procuram ainda dar conta do imperativo de uma "limpa na cidade", atuando como 'polícia dos menores' já que nenhuma criança (que não é qualquer criança²) pode estar no centro da cidade. Segundo Coimbra (2001), a modernidade exige cidades limpas e assépticas, que tirem de visibilidade crianças que se tornem sinal de perigo à ordem instituída, crianças que passam a ser menores, perigosos, como os dois "pretinhos" que constantemente são denunciados por andarem na rua, roubarem e serem usuários de drogas. Aqueles que "não têm jeito". E se não têm jeito, nem condições na vida, teriam possibilidade de quê? Apenas de roubar, se drogar, traficar, ser morto? No discurso do CT, o sistema falido não ofereceria mais possibilidades. Sistema que parece falecido, junto com as esperanças dos sujeitos.

O próprio C'T diz que não há o que fazer com estes "piás", apenas esperar que completem 12 anos para serem recolhidos. Ou seja, não acreditam nas possibilidades de laço social e, consequentemente, em políticas públicas eficazes. Nesse sentido, só resta recolhê-los do próprio mundo que os produz, para que, confinados, dêem sossego para a cidade. Equem irá oferecer condições de vida a todas essas crianças, quando aqueles que devem zelar pelos seus direitos também não mais conseguem vê-las como crianças? Stahlschimidt, Cintra e Svirski (2007), ao traçar um paralelo com as antigas "roda dos expostos", nos chamam atenção para pensar a roda contemporânea da atualidade. Não estarão nossas redes de proteção à criança e adolescente operando como um dispositivo que (re)afirma a desresponsabilização e autonomia do cuidado? Se antes o cuidado era assumido conjuntamente, hoje parece circular, pular, passar de lá para cá, em um ir e vir de constantes encaminhamentos.

Equanto mais se atendem a demandas, com encaminhamentos preestabelecidos, mais constantes elas se tornam, produzindo o que Kuhn (2008) chama de um faz de conta na relação entre CTs e famílias denunciadas (que aqui transpomos também à relação com os serviços públicos de Saúde e à chamada "escuta" solicitada aos estagiários de Psicologia). Nesse faz de conta, é tecida a resolutividade de determinado problema, pautada em uma solução automática de encaminhamento à “escuta psi” ou aos serviços de saúde pública (geralmente serviços que ofereçam acompanhamento psicológico), para neles permanecerem em uma fila de espera interminável.

Também capturado pelas práticas de disciplinarização, o CT, por sua vez, captura práticas do sistema judiciário que, produtoras de ações que incidem na integralidade da vida, fazem uso de "normas universais", sem considerar as condições diversas em que vivem os sujeitos, pois quando as famílias procuram os órgãos de assistência, como o CT, é destacado o modo de funcionamento interno - os conflitos intrafamiliares - e não a possível falta de políticas públicas (Nascimento \& Sheinvar, 2007, p. 157). As autoras salientam que

o ECA propõe um novo ordenamento político, uma outra prática que não é fundamentada nem no atendimento sistemático nem na sentença jurídica, mas na leitura política dos casos de violação dos direitos, a fim de que sejam oferecidas ou criadas condições ao cumprimento da lei.

Mas se no próprio órgão, que tem autonomia para pensar a produção de políticas públicas, priorizam-se produções de soluções individuais, que outros territórios demarcarão os movimentos em direção as ações reivindicatórias?

\section{PSI: possíveis lugares?}

Que ferramenta eu uso pra viver
Como é que eu faço pra ajudar você

(Dunca \& Luiz, 2005)

Por que caminhos pensar o lugar da psicologia nesse contexto? Problematizar demandas e nossa própria implicação nos parece uma ferramenta de intervenção possível, como sugere Coimbra e Nascimento (2007).

No ritmo das urgências, os casos encaminhados à "escuta" dos estagiários incidiam sobre o comportamento dos alunos, encaminhados pela escola. Uma das intervenções possíveis foi justamente problematizar as demandas escolares, atravessadas pela

2 Como nos demonstra Matos e Torralba (2002), são os menores, mulatos, pretos; diferentes das crianças, na maioria, brancas, com condições de vida e, portanto, futuros cidadãos. 
pobreza das famílias, bem como instigar o diálogo da rede de atendimento à infância, objetivando abrir brechas nos instituídos. Como aponta Scheinvar (2008), é uma forma de romper com a lógica pela qual não se analisam os processos que produzem tais situações.

Ao contextualizar as práticas psi no campo político social, Coimbra, Ayres e Nascimento (2008) nos instigam a pensar a centralidade que assumiu o indivíduo ao longo da história, assim como na separação entre o que pertenceria ao saber psi (interior do sujeito) e ao saber social (exterior). A demanda aos estagiários por "escuta" centra-se na busca das causas da problemática dentro do sujeito. Há uma psicologização diante de questões sociais acompanhada pela familiarização das problemáticas.

A "escuta", endereçada às questões definidas pelo CT como mais graves, ${ }^{3}$ assumiam quase que exclusivamente o objetivo de averiguar qual o melhor encaminhamento para o caso ou os "casos onde se vê que o sistema não dá conta". Reflexões sobre o processo que produz tais excessos tornaram-se imperiosas, embora a resposta estancasse no "sistema falido". Sistema que parecia pairar em algum lugar distante...

E nós, profissionais psi, estaremos nesse lugar de quem tenta colocar a vida em seu lugar? $\mathrm{Na}$ análise de nossas implicações, não estaríamos contribuindo (do lugar protegido de especialistas) com o acúmulo das demandas, com a culpabilização das famílias, a manutenção da norma e a pedagogia do cuidado/controle pela avaliação do que está certo ou errado, normal ou com problemas? Como nos traz Cruz (2006), perpassa nossas práticas o questionamento de como trabalhar com os programas de orientação e apoio sociofamiliar de forma a promover a autonomia, os direitos das famílias, sem que esta ação se transforme em mais um veículo de controle? A tentativa de sair do lugar de especialistas, transpondo a comodidade do instituído espaço da "escuta", nos colocou um desafio expresso no questionamento (nosso e do CT) do que, então, seria possível a psicologia nesse contexto? Propostas (advindas da análise institucional) que instigam o questionamento das demandas se tornaram possibilidades desconhecidas, incomodando o funcionamento do CT. Nesse movimento, a escuta se tornou um dispositivo para a problematização dos encaminhamentos. Se a cristalização das práticas se encontra centrada no indivíduo e suas famílias, Cruz (2006) propõe colocar em dúvida 'as verdades' cotidianamente ouvidas e desacreditar as verdades que vamos construindo, desvencilhando-nos, por exemplo, dos binômios famílias capazes/incapazes, normais/patológicas, estruturadas/desestruturadas. Talvez essa seja uma forma de se estabelecer novas relações entre os serviços e a famílias, calcadas na capacidade, na potência dos sujeitos.

Eis um desafio: propor ações estratégias que se coloquem como dispositivos para potencializar os sujeitos. Talvez seja esse um compromisso psi possível: possibilitar espaços, ser e oferecer dispositivos à sensibilização de olhares ainda não experenciados, ou "esquecidos", como o olhar do estranhamento sobre aquilo que, aos nossos olhos, está sendo naturalizado e, nesse movimento, ser capaz de problematizar fazeres, posturas, escutas, modos de estar, e então reinventar, se preciso for, outros modos mais comprometidos com o cuidado pela (e com a) vida.

\section{Referências}

Brasil. Presidência da Republica. (1990). Lei n. 8.069 de 13 de julho de 1990. Dispõe sobre o Estatuto da Criança e do Adolescente, e dá outras providências. Diário Oficial [da] Republica Federativa do Brasil, Brasília, DF, 13 jul. 1990. Recuperado em 2 ago. 2009, em http://www6.senado.gov.br/legislacao $/$ ListaPublicacoes.action?id $=102414$

Bulcão, I. (2002). A produção de infâncias desiguais: Uma viagem na gênese dos conceitos 'criança' e 'menor'. In M. L. Nascimento. (Org.). Pivetes: A produção de infâncias desiguais (pp. 61-73). Rio de Janeiro: Oficina do Auto.

Coimbra, C. M. B., Ayres, L. S. M., \& Nascimento, M. L. do. (2008). Construindo uma psicologia no judiciário. In C. M. B. Coimbra, L. S. M. Ayres, \& M. L. do. Nascimento. (Org.). Pivetes: Encontros entre a Psicologia e oJudiciário (pp. 25-38). Curitiba: Juruá.

\footnotetext{
3 Como o abuso sexual, embora o encaminhamento mais solicitado à "escuta" tenha sido relacionado à demanda escolar. .
} 
Coimbra, C. M. B. \& Nascimento, M. L. do. (2007). Sobreimplicação: Práticas de esvaziamento político? In E. M. M. Arantes, M. L. Nascimento, \& T. M. G. Fonseca. (Org.). Práticas PSI inventando a vida (pp. 27-38). Niterói: UFF.

Coimbra, C. M. B. (2001). Operação Rio. Rio de Janeiro: Oficina do Autor e Intertexto.

Cruz, L. R. da (2006). (Des)articulando as políticas públicas no campo da infância: Implicações da abrigagem. Santa Cruz do Sul: Edunisc.

Duncan, Z., \& Luiz, P. (2005). Música Braços Cruzados. [gravada por Zélia Duncan]. Álbum Pré-pós-tudobossa-band. [CD]. Rio de Janeiro: Universal Music.

Heckert, A. L. C., \& Barros, M. E. B. de. (2007). Fracasso escolar: Do que se trata? Psicologia e educação, debates "possíveis". Aletheia, (25), 109-122.

Kastrup, V. (2007). O funcionamento da atenção no trabalho do cartógrafo. Psicologia \& Sociedade, 19(1):15-22.

Kehl, M. R. (2003). Em defesa da família tentacular. Recuperado em: 21 maio 2008, em http://www. mariaritakehl.psc.br/resultado.php?id=

Kuhn, S. M. (2008). Saber, resistência e autoria: Encontros do conselho tutelar com famílias denunciadas. Dissertação de Mestrado, Programa de Pós-Graduação em Psicologia Social e Institucional, Universidade Federal do Rio Grande do Sul, Porto Alegre.

Matos, M., \& Torralba, R. (2002). Intervindo nas práticas de alguns personagens que atuam na área da infância e juventude. In M. L. Nascimento. (Org.). Pivetes: A produção de infâncias desiguais (pp. 74-82). Rio de Janeiro: Oficina do Autor.

Nascimento, M. L. do, \& Scheinvar, E. (2007). De como as práticas do conselho tutelar vêm se tornando jurisdicionais. Aletheia, (25), 152-162.

Scheinvar, E. (2006). A família como dispositivo de privatização do social. Arquivos Brasileiros de Psicologia, 58(1) 2006. Recuperado em: 14 fev. 2008, em http:// www.psicologia.ufrj.br/abp/
Scheinvar, E. (2008). Demanda social e crise dos ideais: Que lugar para o judiciário? In C. M. B. Coimbra, L. S. M. Ayres, \& M. L. Pivetes: Encontros entre a psicologia e o judiciário. (pp. 177-182) Curitiba: Juruá.

Stahlschimidt, A. P. M., Cintra, M. de, \& Svirski, A. C. (2007). A Reinvenção da Roda. Correio da APPOA, (158), 5-11.

Recebido: 22/09/2009

Received: 09/22/2009

Aprovado: 20/10/2009

Approved: 10/20/2009 